\title{
The Development of A Power Recycling Prototype for Renewable Energy using DC Motor
}

\author{
Wan Nor Shela Ezwane Wan Jusoh, Md Razak Daud \\ Mechanical Department, Politeknik Tuanku Sultanah Bahiyah \\ 09000 Kulim, Kedah \\ Email: $\underline{\text { shela@ptsb.edu.my, md_razak@ptsb.edu.my }}$
}

\begin{abstract}
Energy consumption is an important part of life today because without the power a work cannot be done. The energy used today will be lost or waste without renewable energy or power recycle back. In reality, energy use has always had a noticeable impact on the environment. Overconsumption of energy is the main trigger for the global warming that is now threatening to cause devastation in many areas of the world. Each year, electricity consumption in Malaysia is always an increase. This can contribute to the occurrence of global warming. This project will be designed for renewable energy or recycle power to avoid waste of energy from lost. Also, this project consider regarding the Green Technology without polluting the environment. The objective is to develop a prototype or hardware that aims to renewable energy using the $12 \mathrm{~V}$ DC Motor as a generator which is use rear shaft of table fan as a medium to drive the $12 \mathrm{~V}$ DC Motor and also to analyze the power consumption of table fan before and after install with hardware. The methods used to design the connector and DC motor holder is using a solidwork software, then construct the circuit simulation using a proteus software and also use a microcontroller PIC16F877A as a controller. The result obtained from the testing and experiments by integrating the hardware part, electrical part and software part. Finally, with the development of a power recycling prototype for renewable energy using DC Motor application, the wasted energy can be reused from conversion to other energy and energy can be used as renewable energy.
\end{abstract}

Key words: renewable energy; electricity consumption

\section{INTRODUCTION}

Traditionally, many people are not aware of the importance of renewable energy and some of them still no care about the renewable energy. The government is encouraging to intensity the use of renewable energy in power generation. This is the government is desire to expand the development of the renewable energy[1]. Renewable energy is intended to replace the raw materials used in the present. The supplies of fossil energies, such as oil, natural gas and coal, are limited. They will be depleted within a few decades and then cease to exist. Renewable energies are also referred to as 'regenerative' or 'alternative' energies. Other renewable energies include wind power, biomass, the natural heat or the earth and solar energy [2].

The development of renewable energy sources is important for the future of the country and health of the environment. The existence of the renewable energy is caused by energy resources use today will be reduced or deplete. Several of the traditional sources of energy, such as fossil fuels, are being depleted at faster rates. Technologies required to harness other, less traditional sources, such as renewable energy, have not kept pace with the rising demands of developed and more significantly developing countries [3]. Global climate change is one of cause the existing of renewable energy. Conversely, global climate change, believed to correlate to the accumulation of greenhouse gases in the atmosphere, poses an even more urgent and demanding set of questions. These are related to five predicting reliably the impact of carbon dioxide $(\mathrm{CO} 2)$ on the global temperature and anticipating the impact of global warming on life and health of the planet [4].

Next, there are several ways to produce the renewable energy in which it is derived from changes in the form of energy by natural sources. Examples of renewable technologies consist of solar, wind energy, geothermal energy and biomass[5]. Also, for various sources of energy, e.g. solar, wind, hydraulic, biomass, 
organic wastes, biofuels, and combined heat and power provide a simple, sustainable, effective solution for the conservation of valuable non-renewable fossil resources without resulting in environmental pollution [6].

\section{MATERIALS AND METHODS}

In the mechanical part, there are several components should be required such as DC Motor, connector for rear shaft of table fan and DC Motor holder. The mechanical part designed using solidwork software. Firstly is designing the connector which is to connect the rear shaft of table fan to the $12 \mathrm{~V}$ DC Motor. Then design the DC Motor holder and fabricating through the Rapid Prototyping Machine.
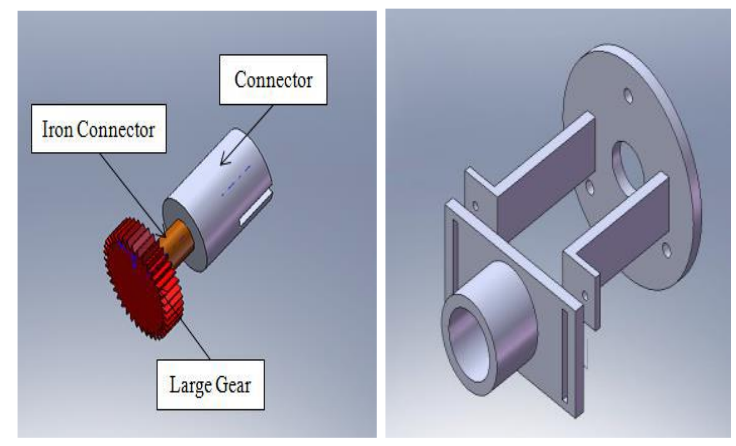

(a)

Fig.1 (a) Connector; (b) DC Motor Holder

In electrical part the process of designing the circuit is start from sketching diagram and design the circuits by using Circuit Wizard software. Also, the circuit can be print on PCB. It consists three circuit which is voltage doubler circuit, voltage divider circuit and voltage divider circuit.

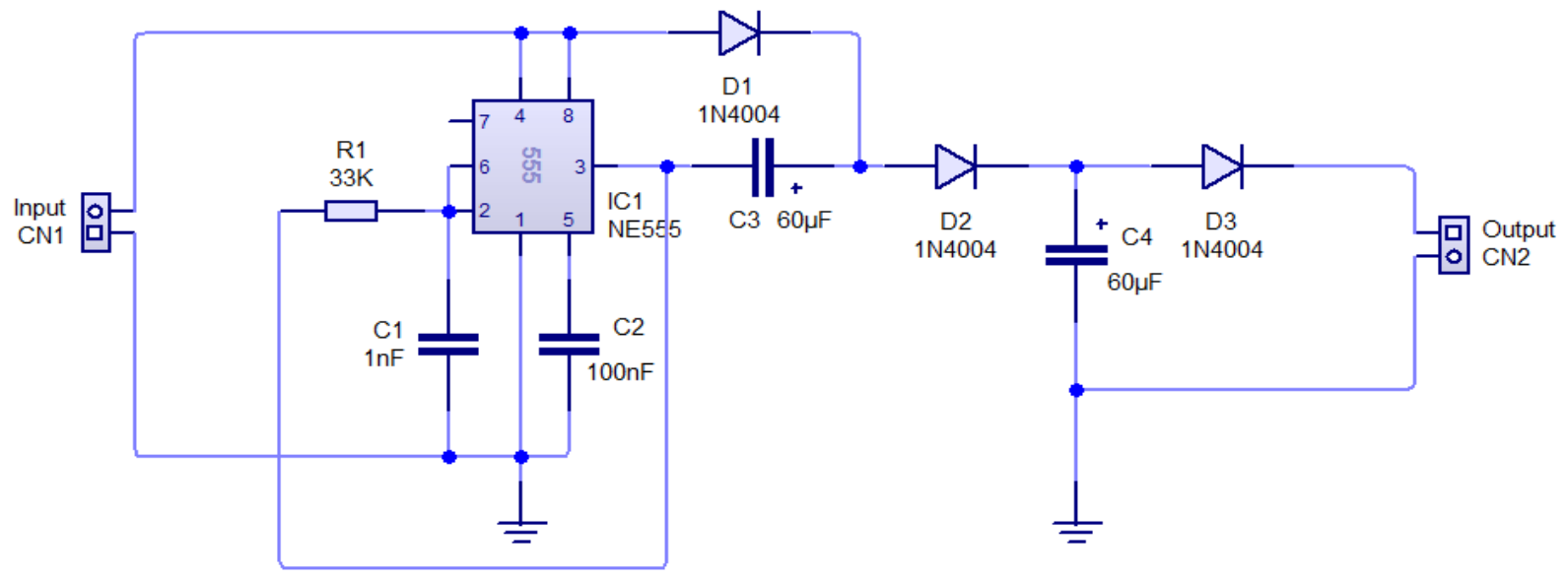

Fig.2 Voltage Doubler circuit schematic diagram

Software part is implementation for LCD display with microcontroller and MicroC compiler is used to program the PIC16F877A microcontroller. Also, Proteus software is used to simulate the circuit in order to performing specification function. This simulation used to trace the problem and error for programming in simulation. 
Wan Nor Shela Ezwane Wan Jusoh \& Md Razak Daud/ Journal of Engineering and Science Research, 2 (6) 2018, Pages: $50-54$

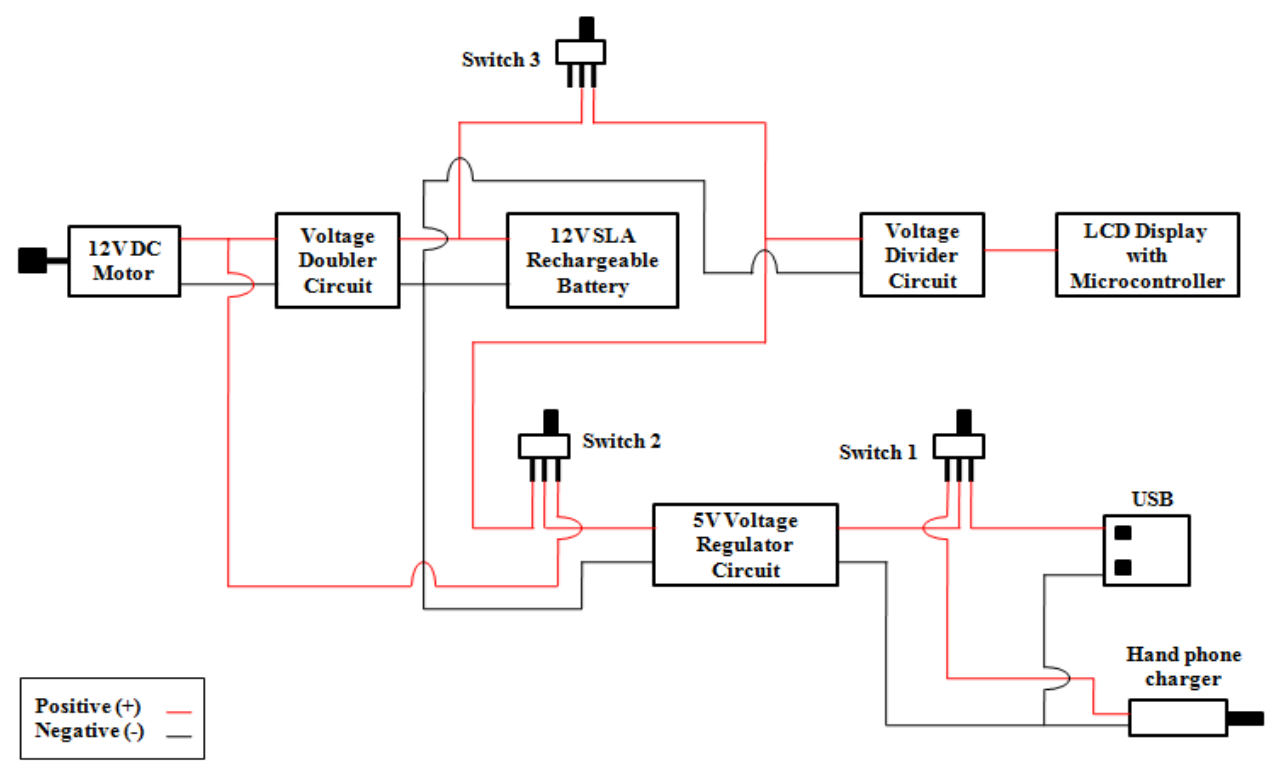

Fig.3 Simulation connection diagram for all circuit

\section{RESULT AND DISCUSSION}

The experiment is to determine the voltage and current output directly connected with $12 \mathrm{~V}$ DC Motor. The time for data sampling was took by every second. The following table shows the data and result that have been recorded from FLUKE Power Quality Analyzer during experiment session.

Table 1. Data sampling voltage and curre 
Wan Nor Shela Ezwane Wan Jusoh \& Md Razak Daud/ Journal of Engineering and Science Research, 2 (6) 2018, Pages: 50-54

\begin{tabular}{|c|c|c|}
\hline \multirow{2}{*}{ Time (sec) } & \multicolumn{2}{|c|}{ Connected directly with 12V DC Motor } \\
\cline { 2 - 3 } & Voltage (V) & Current (mA) \\
\hline 0 & 2.41 & 27.67 \\
\hline 8 & 2.42 & 27.70 \\
\hline 16 & 2.44 & 27.72 \\
\hline 24 & 2.44 & 27.75 \\
\hline 32 & 2.45 & 27.75 \\
\hline 40 & 2.45 & 27.73 \\
\hline 56 & 2.46 & 27.74 \\
\hline 64 & 2.45 & 27.71 \\
\hline 72 & 2.43 & 27.64 \\
\hline 80 & 2.45 & 27.67 \\
\hline 88 & 2.44 & 27.77 \\
\hline 96 & 2.42 & 27.86 \\
\hline 104 & 2.42 & 27.89 \\
\hline 112 & 2.41 & 27.82 \\
\hline 120 & 2.44 & 27.72 \\
\hline 128 & 2.45 & 27.68 \\
\hline 136 & 2.43 & 27.73 \\
\hline
\end{tabular}

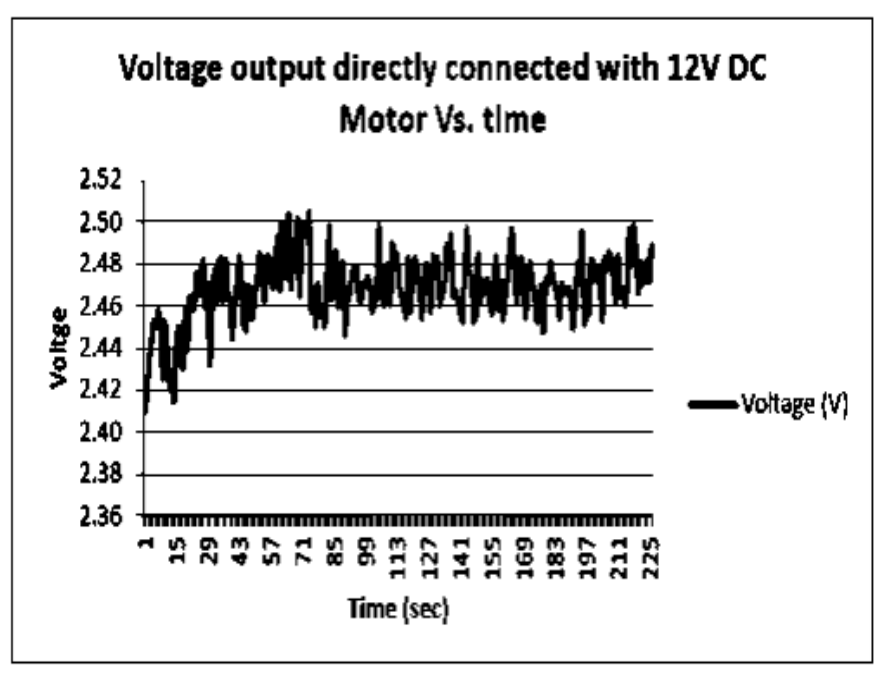

(a)

Fig.4 (a) Graph of voltage output directly connected with 12V DC Motor vs. Time 
Wan Nor Shela Ezwane Wan Jusoh \& Md Razak Daud/ Journal of Engineering and Science Research, 2 (6) 2018, Pages: 50-54

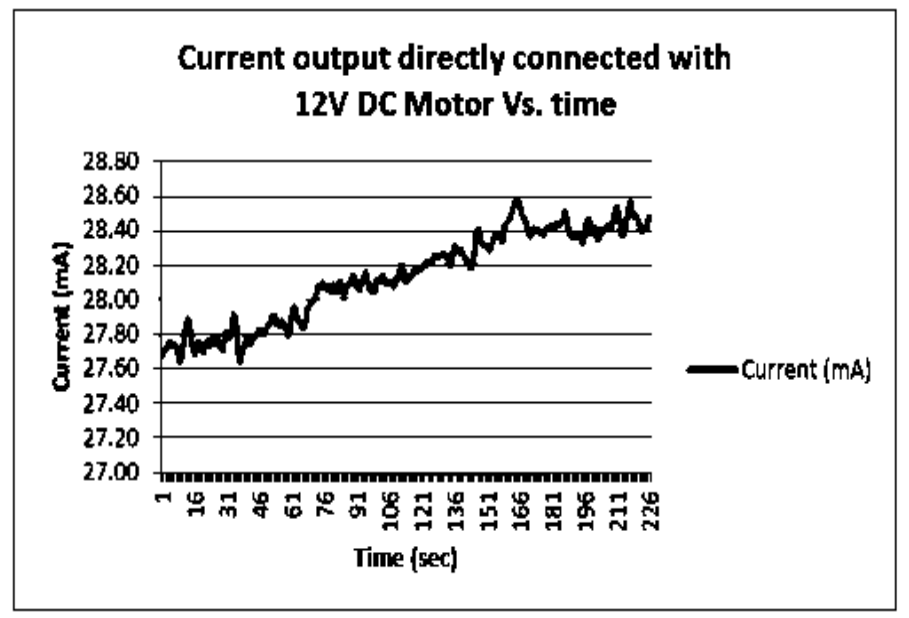

(b)

Fig.4 (b) Graph of current output directly connected with 12V DC Motor vs. time

The graph in the experiment shows the voltage and current directly connected with $12 \mathrm{~V}$ DC Motor versus time. The graph is build from the data that taken from measurement of FLUKE Power Quality Analyzer. From the Fig.4, for graph voltage the maximum output voltage can be produce by $12 \mathrm{~V}$ DC Motor if directly connected is about $2.50 \mathrm{~V}$ while for graph current the maximum current can be produce is about $28.60 \mathrm{~mA}$. As a conclusion, the voltage that produces from directly connected with $12 \mathrm{~V}$ DC Motor is not enough to charge the $12 \mathrm{~V}$ SLA rechargeable battery because to charge the battery, the input voltage must be higher than battery voltage.

\section{CONCLUSION}

Based on the situation, this project was designed to reused back energy wasted by development of a power recycling prototype for renewable energy using DC Motor application. This project intended to reused back energy wasted from table fan to convert it to other energy that is conversion energy from mechanical energy to electrical energy. Using the rear shaft of table fan that connected to $12 \mathrm{~V}$ DC Motor, when the table fan rotates it will also rotates the $12 \mathrm{~V}$ DC Motor and produce electricity. The electricity that produced from $12 \mathrm{~V}$ DC Motor will be used to charge the 12V SLA rechargeable battery or also can be used directly for low power application such as USB LED lamp, hand phone charger and others.

\section{ACKNOWLEDGMENT}

The authors would like to express their thanks to COT PTSB and JPPKK for financial support. Thanks also to the Mechanical Department of PTSB for the laboratory facilities.

\section{REFERENCE}

[1] Anne Mackzulak, Renewable Energy Sources and Methods, pp. 97-108, 2010.

[2] Volker Quanschning, Renewable Energy and Climate Change, 1st edition, Chichester : John Wiley \& Sons, 2010.

[3] Ahmed F.Ghoniem, Needs, resources and climate change : Clean and efficient conversion technologies, Progress in Energy and Combustion Science, pp. 15-51, 2011.

[4] A. Chel, G. Khaushik, Renewable Energy for Sustainable Agriculture, 2010.

[5] Jongwoon Park, Jongho Lee and Dongchan Shin, Power Recycling of Large-Area OLEDs Using Solar Cells, Journal of Display Technology, pp. 247-251, 2010.

[6] M.S. Guney, K.Kaygusuz, Hydrokinetic energy conversion systems : A technology status review, Renewable and Sustainable Energy Reviews, pp. 29963004, 20 